reduced to white. W. Kïhne, of Heidelberg, has studied tection. These eyes are never placed in a varying light, Lot 2 . Three horses were fed on 3 ib. biscuits and about

these changes in their utmost detail, and has given the since they are all found in deep-sea fishes, that consequently
yellow the name of visual yellow and the white that of visual $\mid$ are subjected to quite modified circumstances of life. The white. (See "Archives of the Physiological Institute in Heidelberg."

I would remark incidentally that, in man and the higher but that we tind in birds, etc., a peculiar colored fat globule. the visual purple exist eimultaneously their quantity is al ways in an inverse ratio, that is, the more chlorophan xanthophane, and photophane, the less the quantity of C. Ayres and W. Kühne, " Archives of the Physiological aboratory in Heidelberg."

In all the above-mentioned animals the visual purple is process of bleaching, but, when we pass down the scale, we soon come to a class where this compound is no longer sensitive to light, hut must exert its influence as a stable py C. Fr. W. Krukenberg, "Arch. d. Physiolog. Inst. in Heidelberg."

One more step brings us to an eye in which the visual
purple is not sensitive; but it is also entirely exterior to the retina, having its seat in the pirment epithelium. This I where it is seen in the shape of long purple crystals, which, when isolated, have a peculiar amoeboid motion in them. effective locomotion in heterogeneous light, the purple sensitive, and, as we have before noticed, goes through
peculiar bleaching process; and it is to this that I wish to call special attention.

In Vol. I., Part 4, of the "Archives " already referred to, Kiuhne has given us the absorption spectra of the visual
purple and the visual yellow. In the case of the purple, the absorption begins at the line $\mathrm{C}$ in the solar spectrum, or near the heat end, and attains its maximum midway be the absorption curve falls rapidly through one degree of the solar scale, allowing all the indigo and purple light to pass
through. In other words, the most actinic light is perfectly transmitted. The spectrum of the visual jellow is radically different from this, and its absorption is much more intense,
allhough its color is not nearly so deep. In this spectrum point the curve mounts very rapidily, and the absorption is complete out to the ultra-violet light; $i$. e., all the actinic The generally-accepted opinion of the present day is that the action by which the terminations of the retinal elements receive their impressions is a photo-chemical one, and, if this
be true, the above-described relation of $t$ 'ie different absorptions of the visual purple and yellow cannot be over-
estimated. We shall find in it at least one direct office for this most important compound to fulfill. albuminord more as to the nature of the purple. It is an
the retina (See "Archive from the black pigment epithelium of
thetriolog. Inst. in Heidel herg." W. C. Ayres and W. Kintuc. W When light has acted on the purple while the eye is in the orbit of a living
animal, having its normal supply of blood, the bleaching of the purple to yellow is easy and comparatively rapid, whereas a further action, resulting in the reduction of the yellow to white, is difficult and slow. Also, as is aturial
to suppose, the restitution of the yellow to its prirnitive purple condition requires but little time or expenditure of yellow is very tardy.

Now, suppose that an eye has been in a bright light for
some time and it is brought suddenly into a dark room-the some time and it is brought suddenly into a dark room-the
common experience is, it does not sec; but, after having recommon experience is, it does not sec; but, after having re-
mained for some time in a room not quite dark, we begin to distinguish objects which before were indiscernible. What
must necessarily bave been the condition of the retina during this change? When the eye was in the light a great portion of the purple had been reduced to yellow, and the yellow was portion of the solar spectrum, so that but little actinic light reached the cones; and the retina was working under the modified condition of great absorption of photo-chemical
rays. When the eye was placed suddenly in the dark there must have been so much visual yellow that it absorbed nearly or quite all the light that passed into the eye, and, Now, the known condition is, that under such circumstances the yellow is rapidly transformed into purple, and the constitution of the purple lets all the chemical rays be
transmitted. We then notice that we begin to see a little at first, and then more and more; and the time which we rethe visual yellow into visual purple. We have found, by actual examination of the retine of animals, that when the eye is accustomed to the dark it is rich in the purple pig-
ment, and the yellow is entirely absent. Of course a reversed relation is gone through with when an eye is changed
from the dark back into the ligrlt; it does not see, and the from the dark back into the liglht; it does not see, and the condition of the retina will fully explain the cause of its
incapacity. Having been in the dark, the purple is in excess,
and all the chemical rays are being transmitted; the eye, being and all the chemical rays are being transmitted; the eye, being the effect is that the eye will be overpowered and "dazzled." A rapid reduction of the purple to the yellow commences light will be absorbed, and the retina will hegin to appreciate objects which it could not before. The time agrees in sent

this transformation also.
If we wish to draw any conclusion from these facts, we
are most certainly justitied in saying that at least one office are most certainly justitied in saying that at least one office
of the visual purple is to enable the eye to accustom itself to any circumstance, and by a conitinual self-adjustment to keep itself fitted to work to the true advantage under all conditions. The visual purple, when sensitive to light,
would then be a conservative compound, so constituted as to allow a moredelicate photo-chemical substance in the cones to
produce excitations of the terminal retinal elements; or. if
we hold the theory that the sensitive action of the retina in we hold the theory that the sensitive action of the retina in
the perception of light results from the direct vibrations of the light waves, the action of the purple wonld, neverthe-

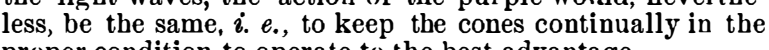
proper condition to operate to the best advantage.
All eyes in which the purple is a stable pigrnent are im.
perfect, and so far they bave been found only in fishes. The result would be the same whether the pigment were situated
in the rods or in the epithelium, since, in both cases, each in the rods or in the epithelium, since, in both cases, each
cone would be surrounded on all sides by a corona of pig-
ment, and its absorption would accomplish the same procornea of these fishes is of itself pigmented yellow, and the faces are not concentric would produce a high degree of stigmatism, and any such delicate arrangement as a sensitive purple would be superfluous, and conseq
pensed with by nature. $-N$. $Y$. Medical Journal.

ME'TEOROLOGICAL USE OF THALLIUM PAPERS.

SchoEne bas given in a subsequent paper, the results of extended series of experiments on the use of thallium pe atmosphere, whether it be hydrogeth peroxide alone, or hixed with ozone, or perhaps also with other constituents
itherto unknown. The objection to Schönbein's ozonometer (potassium iodide on starch paper) and to Houzeau's zonometer (potassium iodide on red litmus paper) lies in the act that their materials are hygroscopic and their indications
vary widely with the moisture of the air. Since dry ozone (hes not act on these papers, they must be moistened; and then the amount of moisture varies the result quite as much as
lhe arger amount of oz. Indeed, attention has been called to the he erroneous opinion advanced that ozone is formed whe water is finely divided. And Böttger bas stated that ozone
is formed when ether is atomized; the fact being that the is formed when ether is atomized; the fact being that the ther. Direct experiments with the Schönbein ozonomete and the psychrometer gave parallel curves; whence the author regards the former as only a crude hygrometer. These ot requiring the presence of moisture, and the color thereore being independent of the hygrometric state of the air.
Moreover, when well cared for the papers undergo no farher change of color and may be preserved indefinitely. The author prepares the thallium paper a few days before
use, by dipping strips of Swedish filtering paper in a solution
f thallous hydrate, and drying. The solution is prepared by pouring a solution of thallous sulphate into a boiling soluthe resulting solution of thallous hydrate being concentrated in vacuo until 100 c.c. contains 10 grammes Tl (OH). Foruse
he strips are hung in the free air in a close vessel. preferably over caustic lime, for twelve hours. Other papers are
used, made with a two per cent. solution. These are exposed for thirty-six hours. The coloration is determined by omparison with a scale having eleven degrees of intensity
upon it. Compared with Schönbein's ozonometer, the re upon it. Compared with Schonbein's ozonometer, the re
show that the greatest effect is in the daytime, the iodist papers that it is at night. Yearly curves show that the forThe iodide curve follows closely that of relative humidity Touds, and rain; the thallium curve stands in no relation to
A table of results for the year 1879 is given in monthly A table of results for the year 1879 is given in monthly
means, of the two thallium papers, the ozonometer, the re G. F. B., in Ber. Berl. Chem. Ge.e.
.

ANALYSIS OF FORAGE BISCÚITS THE forage biscuits which form the subject of the followpartment by the Assistant Commissary General, Calcutta. nd weighed on an average 100 grms. each. A physical ex mination resulted in the detection of linseed, neas, and
usks, not unlike those of barley. The marked indications phosphoric acid and iron, subsequently found in the ash so favored the riew of the presence of this cereal.

\begin{tabular}{|c|c|c|c|}
\hline & & B. & Mean. \\
\hline & $13 \cdot 611$ & $13 \cdot 721$ & $13 \cdot 666$ \\
\hline Albuminoic & $15 \cdot 514$ & $15 \cdot 673$ & 15.534 \\
\hline Carbohydrates. & $57 \cdot 525$ & $53 \cdot 380$ & 86.953 \\
\hline Fiber........... & 1.022 & $1 \cdot 453$ & $1 \cdot 237$ \\
\hline Fot & $7 \cdot 326$ & 7920 & 7.623 \\
\hline Ash. & 5.002 & 4.853 & 4.927 \\
\hline
\end{tabular}
Albuminoids $=\mathbf{N} \times 6.33$. Nitrogen was estimated by Varrentrup and Will's method, a long combustion tube being acid, the chloride being weighed as the ammonic-platinic The ash was of a reddish color, and contained iron, phosphoric, sulphuric, and traces of nitric and carbonic acids,
together with lime, etc. Chloride of sodium was present to the extent of 0.806 per cent. calculated on the biscuits, and
therentime was estimated in a portion which had been charred at a temperature below redness. The albuminoids, or nitrogen-
ous constituents, are present to the extent of nearly 16 per cent. Grain Cicer arietinum, on which horses are largely fed in India, contains $22 \cdot 7$ per cent., peas 23 to 28 per cent. he nitrogenous principles are, therefore, fairly repre Fat is

Fat is present in rather larger amount than is usual in the
iet of horses. Grain, barley, and oats contain $3 \cdot 7,2 \cdot 7$, and iet of horses. Grain, barley, and oats contain $3 \cdot 7,2 \cdot 7$, and
.5 n the food might disagree after a time; but this is a
which can only be decided after actual experiment. which can only be decided after actual experiment.
The linseed was probably in the form of meal, after re-
moval of most of the oil, and was most likely added as a e same time linseed is nutritious und assists in the formaof fat and muscle.

I have recently, through the courtesy of Messrs. Lord \&
o., Calcutta, been furnished with a copy of the extract of the proceedings of a committee assembled at Meerat in ne last, to report on these biscuits. Nine horses were seshape, size, and condition, and all subjected to the same treatment as regards work. They were watered three times
a day before each feed; none of them had any bedding. day before each feed; none of them bad any bedding.
Lot 1 . Consisting of three horses, were fed on 4 see Lot 1. Consisting of three horses,
grain and about 15 seers grass daily.
By C. J. II. WARDEN, Bengal Medical Staff, Chemical material with which to agglutinate the other ingredients,
and so admit of a finer biscuit being manufactured. At

15 seers of grass.
Lot 3 . Three horses were fed on $6 \mathrm{lb}$. of biscuits only, The experiments allowed

The experiments commenced on the 25th March and ter minated on the 18th June. The committee reported that and that with one exception all the horses had kept their condition and carried good coats, so thal they differed in no
way from the other horses in the regiment. -Chem. Neios.

\title{
REFRIGERA'TING MIXTURES.
}

M. A. Dirte has communicated to the Paris Academy of Sciences some very interesting observations on the nature of bydrated salt with an acid. The reduction of temperature
observed when sulphate of soda is mixed with hydrochloric acid is shown to be not simply due to the solution of the salt in the acid. Double decomposition takes place in "accordance with the principle of maximum work." Chloride of hydrochloric acid which is concentrated, is precipitated.
The water which existed in the sulphate of soda in the solid The water which existed in the sulphate of soda in the solid
form is thus set free, and becomes a liquid, absorbing a very arge amount of heat. Now, if the hydrochloric acid is no of the chloride of sodium formed is dissolved; moreover, the decomposition is not complete, and so the maximum reduction of temperature is not obtained. When sixteen parts are mixed with twelve parts of the ordinary commercial
hydrochloric acid the temperature of the mixture is reduced about $33^{\circ} \mathrm{C}$. Similar effects are produced with mixtures of
phosphate of soda, or sulphate of soda, with concentrated nitric acid, and the various alums (which contain a large amount of combined water) and phosphate of soda act like-
wise with hydrochloric acid. The cold produced in these freezing mixtures of acid and hydrated salt is, therefore,
due to the large absorption of beat which occurs when solid (combined) water passes into the liquid (uncombined) state. DETERMINATION OF GOLD AND SILVER IN
ALLOYS AFTER QUARTATION WITH CADMIUM. By Fr. Kraus.

Two portions of the alloy, each of $0 \cdot 25$ gramme, are weighed off and placed with the cadmium in small porce porcelain capsule over the flame, and the metal thrown in The melting together takes place readily, and is complete in a few minutes. By changing with two or three porcelain
capsules, and having a vessel with warm water at hand, in capsules, and having a vessel with warm water at hand, in
which the melt is dissolved when sufficiently cool, twenty to thirty meltings can be executed in an hour. The two metallic granules are now thrown together into a small, long-
necked flask, in which is nitric acid of specific gravity $1 * 00$ a piece of wood charcoal is introduced to prevent bump.
ing-which would rupture the globules-and heat is gently applied. The first solution lasts rather. long, according to
the proportion of gold; $e . g .$, an hour in case of fine gold. The solution is poured off, ihe boiling repeated with nitric acid of specific gravity $1 \cdot 3$ for ten minutes, the liquid again poured off, the irlobiles rinsed with hot water, boiled for five minutes with water, which is poured off, and the flask

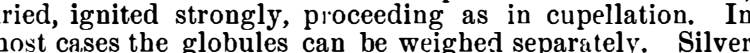
is determined in the solution by titration with ammonium .

\section{DETERMINATION OF SILICON IN IRON AND}

By T. M. Brown.

ONE gramme iron or steel is placed in a porcelain crucible with 25 c. c. nitric acid of 12 specific gravity. When the
reaction is over 25 to 30 c.c. dilute sulphuric acid- 1 part reaction is over 25 to 30 c.c. dilute sulphuric acid- -1 par
acid and 3 water-are added, and the solution is heated the nitric acid is entirely or nearly expelled. When the the contents of the capsule are heated till the crystals are perfectly dissolved. The solution is then filtered as hot as possible, and the residue washed first with hot water, then
with 25 to 30 c.c. hydrochloric acid of specific gravity $1 \cdot 20$ with 25 to 30 c.c. hydrochloric acid of specific gravity $1 \cdot 20$,
and finally again with hot water. After drying and ignition the silica is obtained snow-white and granular.

MANUFACTURE OF PHOSPHORIC ACID. By M. A. Colson.

Naturad phosphates, unground, are dissolved in dilute hydrochloric acid. When the acid has ceased to act the mixed with sulphuric acid enomgh to saturate all the dissolved lime, leaving a mixture of hydrochloric acid, dilute
phosphoric acid, and calcium sulphate. This mixture is phosphoric acid, and calcium sulphate. This mixture is ree acids, which are then concentrated, and the hydrochloric acid is conden columns.
ordinary

COKE OF PETROLEUM

By MM. L. Prunter and Eug. Vareune.

Is the experiments of the authors, the accumulation of weight of the molecule rises to a limit still little known, bu whose richness in carbon is equal or even inferior to that of a progression easy to conceive, the term of the series which diamond. It is known, on the other hand, that the bigher polymers, when submitted to very high temperatures, seem to depolymerize themselves (as liappe
yielding gaseous carbon compounds.

\section{IODINE FROM SEAWEEDS}

By Dr. ThIERCELIN.

The most advantageous weeds for this purpose are the
two varieties of Fucus digitatus. The author states that he bas succeeded in extracting from the plant three per cent. 